\title{
Comunicação
}

(Communication)

\section{Microimenópteros de Musca domestica L. (Diptera: Muscidae) coletados em diferentes substratos em Itumbiara, Goiás}

\author{
[Microhimenopterous of Musca domestica L. (Diptera: Muscidae) collected \\ in different substrata in Itumbiara, Goias] \\ C.H. Marchiori \\ Instituto Luterano de Ensino Superior de Itumbiara - ULBRA \\ Caixa Postal 23-T \\ 75500-000 - Itumbiara, GO
}

\begin{abstract}
Musca domestica L. (Diptera: Muscidae) é a espécie de maior interesse sanitário, atribuído ao seu caráter sinantrópico, sua abundância na região urbana, sua capacidade de desenvolver-se em vários tipos de substratos, seu alto poder reprodutivo e ao fato de ser apontada como veiculadora de patógenos ao homem e aos animais (Nakano e Leite, 2000). Por isso, novas técnicas de controle têm que ser estudadas visando ao controle dessa mosca de interesse em saúde pública (Marchiori et al., 2000a).
\end{abstract}

Além dos inseticidas, também podem ser usados, como controle dos insetos, os chamados reguladores naturais tanto na agricultura como em áreas de criação animal (Silveira et al., 1989).

Os parasitóides são agentes responsáveis pela redução das populações de moscas que proliferam em esterco (Rueda e Axtell, 1985), cadáveres e carcaças de animais. Pelo fato de os parasitóides ocuparem um nível trófico superior, eles freqüentemente atuam como fatores determinantes da densidade populacional de seus hospedeiros, graças à grande diversidade de adaptações fisiológicas e de comportamento. Esses insetos são considerados bioindicadores da biodiversidade dos ecossistemas, sendo considerados espécies-chave para a manutenção do equilíbrio das comunidades que os incluem. Além disso, sendo inimigos naturais de pragas agrícolas, podem ser usados em programas de controle biológico (Scatolini e Dias, 1997). O objetivo deste estudo foi conhecer as espécies de parasitóides associadas com Musca domestica L. em vários substratos.

Os experimentos foram realizados na Fazenda da Faculdade de Agronomia e na Chácara Vilela, no município de Itumbiara $\left(18^{\circ} 25^{\prime} \mathrm{S}-49^{\circ} 13^{\prime} \mathrm{W}\right)$, Goiás. Os métodos de captura dos parasitóides estão descritos em Marchiori et al. (2000a; 2000b; 2003).

Foram coletadas 11.403 pupas de $M$. domestica, no período de julho de 1999 a julho de 2003, das quais 74 apresentavam-se parasitadas com 113 parasitóides (Tab. 1). A freqüência de parasitismo foi $0,7 \%$ (74/11403). Fezes de galinha foram o substrato no qual se coletou maior número de pupários de moscas $(68,2 \%)$, provavelmente, atribuído à maior oferta de substrato para alimentação e às condições abióticas favoráveis (umidade).

Pachycrepoideus vindemiae (Rondani) (Hymenoptera: Pteromalidae) foi a espécie mais abundante em pupários de M. domestica (Tab. 1). Pachycrepoideus vindemiae é considerado um parasitóide solitário de numerosos Diptera das famílias Anthomyiidae, Calliphoridae, Muscidae, Sarcophagidae, Tachinidae, Tephritidae e outras. Essa espécie, de ampla distribuição geográfica, também é encontrada na América do Norte e na África (Hanson e Gauld, 1995).

Recebido em 16 de fevereiro de 2004

Aceito em 13 de outubro de 2005

E-mail: pesquisa.itb@ulbra.br 
Tabela 1. Parasitóides de Musca domestica coletados em diversos substratos em Itumbiara, Goiás, no período de julho de 1999 a julho de 2003

\begin{tabular}{|c|c|c|c|c|c|}
\hline \multirow{2}{*}{ Substrato } & \multirow{2}{*}{$\begin{array}{l}\text { Pupas } \\
\text { coletadas }\end{array}$} & \multicolumn{2}{|l|}{ Parasitóides } & \multirow{2}{*}{$\begin{array}{c}\text { Pupas } \\
\text { parasitadas }\end{array}$} & \multirow{2}{*}{ Ocorrência } \\
\hline & & Espécie & $\mathrm{N}^{\mathrm{o}}$ & & \\
\hline \multirow[t]{5}{*}{ Fezes de galinha } & 7779 & Pachycrepoideus vindemiae & 17 & 17 & 0,22 \\
\hline & & Spalangia cameroni & 12 & 12 & 0,15 \\
\hline & & Spalangia endius & 8 & 8 & 0,10 \\
\hline & & Spalangia nigra & 1 & 1 & 0,01 \\
\hline & & Spalangia nigroaenea & 6 & 6 & 0,08 \\
\hline Fezes humanas & 111 & Hemencyrtus herbertii & 5 & 1 & 0,90 \\
\hline Fígado de bovino & 48 & Nasonia vitripennis & 34 & 3 & 6,25 \\
\hline Frango & 45 & Nasonia vitripennis & 5 & 1 & 2,22 \\
\hline \multirow[t]{2}{*}{$\begin{array}{l}\text { Restos de } \\
\text { alimentos }\end{array}$} & 50 & Pachycrepoideus & 9 & 9 & 18,0 \\
\hline & & $\begin{array}{l}\text { vindemiae } \\
\text { Muscidifurax raptor }\end{array}$ & & & \\
\hline \multirow[t]{2}{*}{ Fezes bovinas } & 3370 & $\begin{array}{l}\text { Pachycrepoideus } \\
\text { vindemiae }\end{array}$ & & & \\
\hline & & Spalangia comeroni & 1 & 1 & 0,03 \\
\hline Total & 11403 & & 113 & 74 & \\
\hline
\end{tabular}

Sereno e Neves (1993), ao estudarem a ocorrência natural de parasitóides em pupas de $M$. domestica por $P$. vindemiae e Nasonia vitripennis (Walker) (Hymenoptera: Pteromalidae) em aviários, encontraram prevalência de parasitismo de $1,0 \%$ e 3,7\%, respectivamente.

As freqüências de parasitismo em fezes de galinha, fezes humanas, fezes bovinas, fígado bovino, vísceras de frango e restos alimentares foram de $0,6 \%, 0,9 \%, 20,0 \%, 6,3 \%, 2,2 \%$ e $0,5 \%$, respectivamente. Provavelmente, a maior freqüência de parasitismo observada em fígado de bovino pode ser atribuída às variações na qualidade e na disponibilidade de recursos alimentares ou na densidade dos hospedeiros.

O gênero Spalangia apresenta parasitóides pupais associados a moscas das famílias Muscidae, Calliphoridae, Sarcophagidae, Drosophilidae e Chloropidae, que se desenvolvem em fezes e em carcaça de animais (Gauld e Bolton, 1988).

Hemencyrtus sp. comporta-se como parasitóide de larvas, desenvolvendo internamente no corpo do hospedeiro e emergindo do pupário. Hemencyrtus sp. foi coletado nos seguintes hospedeiros: Chrysomya albiceps, Hemilucilia flavifacies (Calliphoridae), Synthesiomyia nudiseta (Muscidae), Euboettcheria collusor, Oxysarcodexia sp. e Patonella intermutans (Sarcophagidae) (Rueda e Axtell, 1985; Silva, 1991; Marchiori et al., 2000a).

Nasonia vitripennis comporta-se como parasitóide gregário, é ectoparasitóide em pupas de várias espécies de famílias de Díptera, particularmente: Calliphoridae, Muscidae, Sarcophagidae e Tachinidae (Gauld e Bolton, 1988).

Como o uso de inseticidas pode levar à seleção de espécies resistentes, o uso de inimigos naturais, como os parasitóides, pode ser uma alternativa no controle desses insetos, porém novos estudos devem ser realizados para verificarem a utilização dos parasitóides em futuros programas de controle biológico.

Palavras-chave: mosca doméstica, Diptera, Hymenoptera 


\begin{abstract}
The species of parasitoids associated with Musca domestica L. (Diptera: Muscidae) collected in human feces, cattle liver, chicken viscera, cattle dung, chicken manure and food leftovers in Itumbiara, State of Goiás, Brazil, from July 1999 to July 2003, were studied. The pupae were obtained by the flotation method. They were individually placed in gelatin capsules until the emergence of the adult flies or their parasitoids. The overall prevalence of parasitism was $0.7 \%$. The most frequent species was Pachycrepoideus vindemiae (Rondani) (Hymenoptera: Pteromalidae), accounting for 35.4\%.
\end{abstract}

Keywords: fly, Diptera, Hymenoptera

\section{REFERÊNCIAS BIBLIOGRÁFICAS}

GAULD, I.D.; BOLTON, B. The Hymenoptera. Oxford: Oxford University, 1988. 331p.

HANSON, P.E.; GAULD, I.D. The Hymenoptera of Costa Rica. Oxford: Oxford University, 1995. 893p.

MARCHIORI C.H.; CASTRO, M.E.V.; PAIVA, T.C.G. et al. Dípteros muscóides de importância médica e veterinária e seus parasitóides em Goiás. Arq. Bras. Med. Vet. Zootec., v.52, p.350353, 2000a.

MARCHIORI, C.H.; SILVA FILHO, O.M.; BORGES, M.P. et al. Parasitóides de Musca domestica L. (Diptera: Muscidae) de Itumbiara, Goiás, Brasil. Rev. Patol. Trop., v.32, p.263-266, 2003.

MARCHIORI, C.H.; VIEIRA, C.I.S.; CALDAS, E.R. et al. Dípteros muscóides associados com fezes bovinas e seus parasitóides em Goiás. Arq. Bras. Med. Vet. Zootec., v.52, p.354-356, 2000 b.

NAKANO, O.; LEITE, C.A. Armadilhas para insetos. Piracicaba: FEALQ, 2000.
RUEDA, L.M.; AXTELL, R.C. Guide to commom species of pupae parasites (Hymenoptera: Pteromalidae) of the house fly and other muscoid flies associated with livestock and poultry manure. Tech. Bull. North Carolina Agric. Res. Serv., n.128, p.1-88, 1985.

SCATOLINI, D.; DIAS, A.M.P. A fauna de Braconidae (Hymenoptera) como bioindicadora do grau de preservação de duas localidades do Estado do Paraná. Rev. Bras. Ecol., v.1, p.84-87, 1997.

SERENO, F.T.P.S.; NEVES, D.P. Ocorrência natural de microhimenópteros parasitóides de pupas de moscas em aviários. An. Soc. Entomol. Brasil., v.22, p.527-533. 1993.

SILVA, A.R. Himenópteros parasitóides associados a dipteros saprófagos, com especial referência aos Alysiinae (Braconidae). 1991. 54f. Dissertação (Mestrado) - Universidade Federal de São Carlos, São Carlos, SP.

SILVEIRA， G.A.R.; MADEIRA， N.G.; AZEREDO-ESPIN, A.M.L. Levantamento de microhimenoptera parasitóides de dípteros de importância médico-veterinária no Brasil. Mem. Inst. Oswaldo Cruz, v.84, p.505-510, 1989. 